
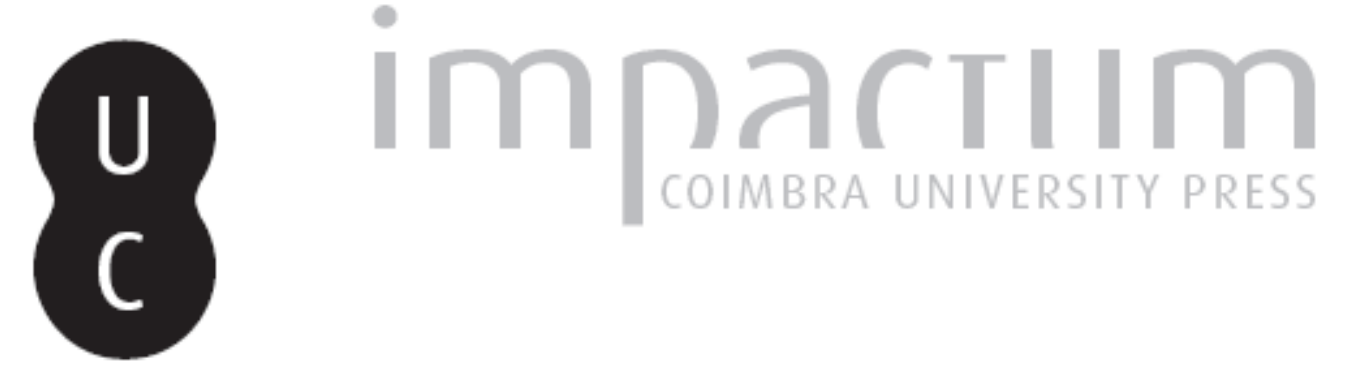

\title{
Análise química não-destrutiva de dois cadinhos achados em Conimbriga
}

Autor(es): $\quad$ Cabral, João M. Peixoto; Araújo, M. Fátima D.; Alarcão, Adília M.

Publicado por: Imprensa da Universidade de Coimbra

URL persistente:

URI:http://hdl.handle.net/10316.2/45681

DOI:

DOI:https://dx.doi.org/10.14195/1647-8657_23_11

Accessed : $\quad$ 26-Apr-2023 14:22:51

A navegação consulta e descarregamento dos títulos inseridos nas Bibliotecas Digitais UC Digitalis, UC Pombalina e UC Impactum, pressupõem a aceitação plena e sem reservas dos Termos e Condições de Uso destas Bibliotecas Digitais, disponíveis em https://digitalis.uc.pt/pt-pt/termos.

Conforme exposto nos referidos Termos e Condições de Uso, o descarregamento de títulos de acesso restrito requer uma licença válida de autorização devendo o utilizador aceder ao(s) documento(s) a partir de um endereço de IP da instituição detentora da supramencionada licença.

Ao utilizador é apenas permitido o descarregamento para uso pessoal, pelo que o emprego do(s) título(s) descarregado(s) para outro fim, designadamente comercial, carece de autorização do respetivo autor ou editor da obra.

Na medida em que todas as obras da UC Digitalis se encontram protegidas pelo Código do Direito de Autor e Direitos Conexos e demais legislação aplicável, toda a cópia, parcial ou total, deste documento, nos casos em que é legalmente admitida, deverá conter ou fazer-se acompanhar por este aviso.

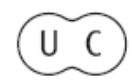


FACULDADE DE LETRAS

INSTITUTO DE ARQUEOLOGIA

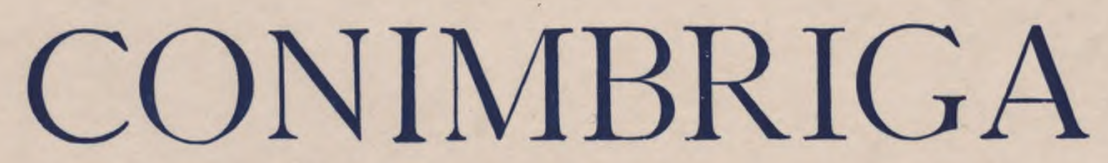

VOLUMEXXIII

UNIVERSIDADE DE COIMBRA

1984 
JoÃo M. PEIXoto Cabral

M. Fátima D. Araújo

Investigadores do LNETI, Instituto de Energia, Departamento de Química

(Sacavém).

Adília M. Alarcão

Directora do Museu Monográfico de Conímbriga.

\author{
ANÁLISE QUÍMICA NÃO-DESTRUTIVA DE DOIS CADINHOS \\ ACHADOS EM CONÍMBRIGA \\ Conímbriga, XXII (1984), p. 159-168
}

RESUmo: Análises não-destrutivas das superfícies exteriores e interiores de dois cadinhos achados em Conímbriga, efectuadas num espectrómetro de fluorescência de raios $\mathrm{X}$ dispersivo de energias, usando fontes radioactivas de excitação, provaram que teriam sido utilizados para preparar ligas de cobre. Num deles encontraram-se indícios claros de que a liga seria de cobre-estanho-chumbo-zinco, contendo como principais impurezas prata e antimonio. No outro, os únicos vestígios encontrados foram de cobre e zinco.

Aвstract : The inward and outward surfaces of two crucibles found in Conímbriga were analysed by non-destructive energy dispersive $\mathrm{X}$-ray fluorescence spectrometry using radioisotope excitation sources. Ths results show that they were used to prepare copper alloys. Clear evidence of a copper-tin-lead-zinc alloy with traces of silver and antimony were found in one of the. The only metals detected in the other crucible were shown to be copper and zinc. 
(Página deixada propositadamente em branco) 


\section{ANÁLISE QUÍMICA NÃO-DESTRUTIVA DE DOIS CADINHOS ACHADOS EM CONÍMBRIGA}

\section{Introdução}

Os achados de cadinhos metalúrgicos em escavações arqueológicas põem, do ponto de vista da arqueometalurgia, essencialmente duas questões: por um lado, a questão de se conhecer a composição química das escórias ou dos resíduos de metais e ligas metálicas que, em geral, contêm; e, por outro lado, a questão de se saberem as composições química e mineralógica dos materiais de que são feitos esses cadinhos, normalmente materiais cerâmicos derivados de argilas [1].

Em ambos os casos visa-se, em última análise, o mesmo objectivo que é o estudo das técnicas de metalurgia extractiva, de fundição de metais, e de preparação de ligas metálicas, utilizadas na Antiguidade. Mas, enquanto a resolução da primeira questão conduz, por via de regra, à obtenção de um maior número de informações sobre essas técnicas, e é da competência do metalurgista, a resolução da segunda limita-se a permitir obter eventualmente indicações sobre a proveniência daqueles materiais e sobre as temperaturas alcançadas na prática das referidas técnicas, sendo da atribuição do investigador de materiais cerâmicos. Daí que se tenha vindo a prestar mais atenção à primeira questão.

Este trabalho constitui a primeira parte do estudo de dois cadinhos pertencentes ao Museu Monográfico de Conímbriga, a qual visa a identificação dos metais que neles teriam sido fundidos.

Ambas as peças foram descobertas na área artesanal, junto do forum, infelizmente fora do contexto [2]; as suas características tipológicas encontram-se já publicadas [3] mas julga-se vantajoso recordá-las aqui. 
O cadinho número 53 (Fig. la) tem uma forma aproximadamente cónica, boca elíptica (dimensões internas - eixo maior: $48 \mathrm{~mm}$; eixo menor: $40 \mathrm{~mm}$ ) e bordo arredondado, identificando-se com os cadinhos do tipo B.3 da tipología adoptada por Tylecote [4]. $\mathrm{O}$ bordo possui uma pequena depressão, situada na região correspondente a uma das extremidades do eixo maior da elipse, a qual tinha certamente a função de vertedoiro, pois ainda se nota na superfície exterior do cadinho, subjacente a essa depressão, uma faixa de tons mais claros a toda a altura do cadinho (de cerca de $50 \mathrm{~mm}$ ), indicativa do escorrimento de material fundido. Este cadinho encontra-se rachado, estendendo-se a racha desde o bordo até cerca de metade da altura. A superfície exterior é irregular e apresenta-se com um aspecto vítreo, multicolor, com predominância do vermelho e do verde azeitonado escuro. A superfície interior, mais regular, mostra-se também com um aspecto vítreo junto ao bordo mas baça na região do fundo. Nesta superfície vêm-se vários pequenos pingos de fundição de cor verde, sobretudo na parte superior.

O cadinho número 54 (Fig. lb) tem uma forma aproximadamente hemisférica, uma altura de cerca de $43 \mathrm{~mm}$, boca circular (diâmetro interno à volta de $24 \mathrm{~mm}$ ) e bordo arredondado, assemelhando-se aos cadinhos do tipo B.l da tipología atrás referida. A superfície exterior apresenta-se na sua maior parte com um aspecto vítreo, de cor cinzenta escura, e é igualmente irregular. A superfície interior, mais regular, é baça, com tons acastanhados no fundo, e não mostra vestígios de pingos de fundição.

\section{Parte experimental}

As análises foram efectuadas num espectrómetro de raios $\mathrm{X}$ dispersivo de energias cujas características se descreveram já em publicações anteriores $[5,6]$. O dispositivo adaptado ao detector de $\mathrm{Si}(\mathrm{Li})$, constituído pela fonte de excitação e os filtros de raios $\mathrm{X}$, foi o mesmo que o indicado nas citadas publicações. Como porta-amostras utilizou-se uma folha de mylar, inserida entre dois anéis de perspex situados na parte superior desse dispositivo. A exci- 
tação foi feita recorrendo a fontes radioactivas anulares, nomeadamente de ${ }^{109} \mathrm{Cd}$ e ${ }^{241} \mathrm{Am}$.

Do cadinho número 53 efectuaram-se várias análises, em particular das seguintes áreas: duma área da faixa de tons mais claros subjacente ao vertedoiro, colocando o cadinho tombado sobre a folha de mylar; doutra área da superfície exterior, diametralmente oposta à primeira; duma terceira área da mesma superfície, situada numa zona intermédia; da área da superfície interior, com o cadinho em posição invertida sobre a referida folha; e de uma pequena lasca que se extraiu da face interna do cadinho, na qual se notavam vestígios de um pequeno pingo de fundição. Neste último caso, analisou-se não só a superfície da lasca onde se encontravam esses vestígios mas também a superfície contrária.

Do cadinho número 54, que estava quebrado em dois fragmentos e não apresentava sinais especiais, fizeram-se do mesmo modo várias análises, designadamente: da superfície exterior em duas regiões diferentes, uma com aspecto vítreo e outra baça; da superfície interior com o cadinho em posição invertida; e das superfícies exterior e interior dos fragmentos.

\section{Resultados e discussão}

$\mathrm{Na}$ Fig. 2 e na Fig. 3 apresentam-se os espectros de raios $\mathrm{X}$ obtidos nas análises da superfície exterior da parede do cadinho número 53, nas regiões anteriormente indicadas, usando as fontes de excitação de ${ }^{109} \mathrm{Cd}$ e ${ }^{241} \mathrm{Am}$ respectivamente. $\mathrm{Na}$ Fig. 4 e na Fig. 5 estão representados os espectros de raios $\mathrm{X}$ respeitantes às análises da superfície interior desse cadinho. Na Fig. 6 e na Fig. 7 apresentam-se os espectros de raios $\mathrm{X}$ concernentes à lasca com vestígios do pingo de fundição, extraída do mesmo cadinho.

Por fim, na Fig. 8 e na Fig. 9 mostram-se os espectros de raios $\mathrm{X}$ resultantes das análises das superfícies exterior e interior dum fragmento do cadinho número 54. Os espectros obtidos nas restantes análises deste cadinho não são apresentados, por não conterem informações complementares nem contrárias às incluídas nas Figs. 8 e 9. 
Comparando os espectros da superfície exterior do cadinho número 53, representados na Fig. 2, verifica-se que eles diferem essencialmente no que diz respeito às intensidades dos picos do cobre (CuKa e CuKp) e do chumbo (PbLa e $\mathrm{PbL}(3)$, as quais são máximas no espectro da região subjacente ao vertedoiro e mínimas no espectro da região oposta. Este facto está igualmente evidenciado na Fig. 3, relativa do mesmo modo à superfície exterior, onde se nota ainda uma diferença no que se refere às intensidade dos picos da prata (AgKa), do estanho (SnKa e $\mathrm{SnK}$ (3) e do antimonio ( $\mathrm{SbKa}$ ) as quais também são máximas no espectro da região subjacente ao vertedoiro. Desses picos, os mais intensos são os do cobre e do estanho ( $\mathrm{CuKa}$ e $\mathrm{SnKa}$ ). Assim, como na excitação com ${ }^{241} \mathrm{Am}$ o rendimento de fluorescência do cobre é muito inferior ao do estanho, e uma vez que os valores da eficiência do detector de $\mathrm{Si}(\mathrm{Li})$ para os raios $\mathrm{X}$ CuKa e $\mathrm{SnKa}$ não divergem grandemente, os resultados das figuras 2 e 3 indicam de forma clara que o material que foi fundido no cadinho número 53 era essencialmente constituído por cobre, contendo algum estanho, isto é, era um bronze. Indicam, além disso, dado que os picos $\mathrm{PbLa}$ e $\mathrm{PbLp}$ embora pequenos são perfeitamente visíveis, que esse bronze conteria ainda uma pequena percentagem de chumbo. Mostram, por último, que ele possuiria como principais impurezas prata e antimonio.

Se compararmos agora os espectros da superfície interior deste cadinho, representados na Fig. 4 e na Fig. 5, com os espectros da superfície exterior na região oposta à subjacente ao vertedoiro (espectros $c$ das figuras 2 e 3), reconhece-se que eles divergem sobretudo nas intensidades relativas dos picos do cobre $(\mathrm{CuKa}$ e CuKp), do zinco (ZnKa e ZnKp) e do chumbo (PbLa e PbL(3), as quais são maiores nos espectros da superfície interior. Não se observam diferenças muito significativas nas intensidades relativas dos picos do estanho (SnKa e SnKfi). Verifica-se, contudo, que as intensidades destes picos no espectro da superfície interior (Fig. 5) são razoavelmente grandes, confirmando que o material que foi fundido no cadinho era um bronze. É de notar que na superfície interior se reconhece a presença não só de cobre, chumbo e estanho, mas também de zinco. Isto sugere que o zinco tenha sido igualmente utilizado como elemento de liga e que a sua presença 
nessa superfície, bem como a sua ausência na superfície exterior, se devam à circunstância de a temperatura de ebulição do zinco ser relativamente baixa $\left(906{ }^{\circ} \mathrm{C}\right)$ e ao facto de a técnica usada na preparação de ligas de cobre-zinco no Período Romano, de que nos ocuparemos adiante, conduzir muito provavelmente à adsorção do zinco nas paredes internas dos cadinhos.

Idênticas ilações se tiram quando se examinam os espectros da Fig. 6 e da Fig. 7, referentes à lasca extraída da face interior do cadinho número 53, numa área onde se notavam vestígios dum pingo de fundição. Com efeito, comparando os espectros $a$, respeitantes à superfície onde se encontram os vestígios desse pingo, com os espectros á, concernentes à superfície contrária, observam-se diferenças nas intensidades dos picos do cobre $(\mathrm{CuKa})$, do chumbo (PbLa e $\mathrm{PbL}(3)$ e do estanho (SnKoc e $\mathrm{SnK}(3)$, particularmente acentuada para o pico CuKa. Essas intensidades são maiores no espectro da superfície onde se encontram os referidos vestígios. Além disso, nos espectros á, que de todos os espectros obtidos são os que melhor representam a composição da parte interna da parede do cadinho, verifica-se que o pico mais importante é o do zinco $(\mathrm{ZnKa})$.

Por outro lado, comparando os espectros da superfície exterior do fragmento do cadinho número 54, representados na parte superior das figuras 8 e 9, com os espectros da sua superfície interior, incluídos na parte central das mesmas figuras reconhece-se que diferem unicamente no que respeita às intensidades dos picos do cobre $(\mathrm{CuKa})$ e do zinco $(\mathrm{ZnKa}$ e $\mathrm{ZnK}(3)$. É de notar (Fig. 8) que enquanto no espectro da superfície exterior o pico do cobre nem sequer existe e o do zinco é muitíssimo pequeno, no espectro da superfície interior já se detecta cobre e o pico do zinco é relativamente acentuado. Note-se, além disso, a fraca intensidade dos picos do chumbo (PbLa e PbLp) e a sua invariância quando se passa da superfície exterior para a interior. É de notar, por último (Fig. 9), a inexistência de diferenças no que se refere aos picos de estanho ( $\mathrm{SnKa}$ e $\mathrm{SnKp}$ ) e o facto de as suas intensidades serem pequenas quando comparadas com as dos picos do bário (BaKa) ou do zircónio ( $\mathrm{ZrKa})$, elementos constituintes do material de que é feito o cadinho. Estes resultados mostram, portanto, que o cadinho número 54 terá sido utilizado muito provavelmente 
para fundir uma liga de cobre que não conteria estanho, nem chumbo, mas apenas zinco.

Repare-se, ainda, que consoante se referiu já atrás não se encontraram diferenças entre os espectros das áreas da superfície exterior do cadinho número 54 correspondentes à região com aspecto vítreo e à região baça, o que leva a crer que a vitrificação que se observa externamente, e que se julga resultar do contacto do cadinho com a cinza do combustível utilizado no aquecimento [1], não é acompanhada por uma variação signifificativa da composição do material constituinte do cadinho mas somente por uma variação de estrutura.

Importa salientar que foi precisamente durante a época romana, por volta dos meados do primeiro século a.C., que se iniciou a produção em larga escala de ligas de cobre-zinco (latões), as quais se destinavam principalmente à cunhagem de moedas [7], embora sejam frequentes os objectos de adorno e uso doméstico e os instrumentos cirúrgicos feitos desse metal, durante o Alto Império. Supõe-se que o processo utilizado nessa produção era o processo da calamina (nome que se dava quer ao carbonato de zinco, quer ao óxido de zinco), o qual consistia em misturar, num cadinho, fragmentos de cobre com carbonato (ou óxido) de zinco e carvão de madeira, e em aquecer a mistura no cadinho fechado a uma temperatura compreendida entre $900^{\circ} \mathrm{C}$ e $1000^{\circ} \mathrm{C}$. Esta temperatura é suficientemente elevada para que o zinco, depois de reduzido ao estado metálico, se evapore (a sua temperatura de ebulição é, como se disse, de $906^{\circ} \mathrm{C}$ ), mas insuficiente para que o cobre funda (a sua temperatura de fusão é de $1083^{\circ} \mathrm{C}$ ). Nestas condições, o vapor de zinco é facilmente absorvido nos fragmentos de cobre. Por último, a mistura seria aquecida a uma temperatura um pouco mais alta, de modo a fundir a liga de cobre-zinco cuja temperatura de fusão é inferior à do cobre puro, e o banho fundido seria agitado a fim de se obter uma liga uniforme [7].

É importante destacar, ainda, que a produção de latões em larga escala não foi acompanhada por uma diminuição da produção de bronzes, os quais continuaram a ser, durante a época romana, as ligas mais importantes de metais não-ferrosos. Contudo, nesse período, passou a ser prática corrente preparar estas ligas adicionando ao cobre não só estanho mas também chumbo (que já se 
começara a juntar anteriormente) e zinco, em percentagens que variavam consoante o fim a que as ligas se destinavam. Com efeito, enquanto muitos dos bronzes forjados romanos apresentam normalmente mais zinco do que estanho, a maior parte dos bronzes vasados possuem mais estanho do que zinco; outra característica destas últimas ligas é conterem uma percentagem considerável de chumbo [8].

Supõe-se que a introdução de zinco nos bronzes se terá feito de maneira semelhante à do processo da calamina, aplicado na produção de latões. É natural, por conseguinte, que os cadinhos utilizados, seja na preparação das ligas de cobre-estanho-zinco, seja na das ligas de cobre-estanho-chumbo-zinco, apresentem entre outros vestígios um teor apreciável de zinco na sua superfície interior, resultante da adsorção de vapor de zinco nessa superfície.

\section{Conclusões}

Os resultados obtidos nas análises químicas da superfície exterior e interior do cadinho número 53, bem como da pequena lasca extraída da face interior, onde se notavam vestígios dum pingo de fundição, provam sem sombra de dúvida que este cadinho teria sido utilizado para preparar uma liga de cobre-estanho-chumbo-zinco. Os indícios dos três primeiros metais estão sobretudo evidenciados na face exterior do cadinho, em particular na faixa vertical de tons mais claros subjacente ao vertedoiro, e no pingo de fundição. Os vestígios de zinco encontram-se na face interior. Há indícios de que essa liga teria como principais impurezas prata e antimonio.

Os resultados obtidos nas análises químicas da superfície exterior e interior do cadinho número 54 mostram que ele teria sido utilizado para fundir uma liga de cobre-zinco (um latão). 


\section{AGRADECIMENTOS}

Os autores agradecem reconhecidamente ao Eng. A. Monge Soares a execução do desenho dos cadinhos que ilustra este trabalho, bem como a leitura crítica do manuscrito.

Desejam exprimir também o seu reconhecimento à Eng. M. A. Gouveia pela corrida do programa DESPAR, no computador PDP 15, usado no traçado dos gráficos representativos dos espectros de raios $X$.

\section{REFERÊNCIAS}

[1] Tylecote, R. F., Metallurgical crucibles and crucible slags, in «J. S. Olin e A. D. Franklin, ed., Archaeological Ceramics», Washington, D.C., Smithsonian Institution Press, 1982, p. 231-243.

[2] As condições de achado destes cadinhos, em camadas remexidas e isoladas, não fazem prova da localização de uma oficina. Todavia, as colecções do Museu integram uma série de objectos e ferramentas descobertas anteriormente por Virgílio Correia, incluindo moldes e algaravizes, que atestam a produção local de artefactos em cobre e ligas deste metal. (Cf. Coleç̧ões do Museu Monográfico de Conímbriga. Catálogo, Coimbra, 1984, p. 33).

[3] Alarcão, J.; etienne, R.; Alarcão, A. M., Ponte, S. da, Trouvailles diverses. Fouilles de Conimbriga, vol. VII, Paris, E. de Boccard, 1978, p. 28-29. Est. IV, 53, 54 (números de Inventário 64.429 e 65.538, respectivamente).

[4] Tylecote, R. F., Metallurgy in Archeology. A Prehistory of Metallurgy in the British Isles, London, Edward Arnold (Publishers) Ltd., 1962, p. 132.

[5] Cabral, J. M. P.; Possolo, A.; Marques, M. G., Non-destructive analysis of reais and fortes of Dom Fernando of Portugal by X-ray spectrometry. «Archaeometry», 21, 1979, p. 219-231.

[6] Cabral, J. M. P.; Araúuo, M. F. D.; Gouveina, M. A., Aplicação da espectrometría de fluorescência de raios $X$ na verificação da autenticidade duma taça de prata. «Rev. Port. Quím.», 22, 1980, p. 71-75.

[7] Craddocк, P. T., The composition of the copper alloys used by the Greek, Etruscan and Roman civilizations. 3 - The origins and early use of brass. «Journal of Archaeological Science», 5, 1978, p. 1-16.

[8] Tyсесоте, R. F., A History of Metallurgy, London, the Metals Society, 1976 , p. 59. 


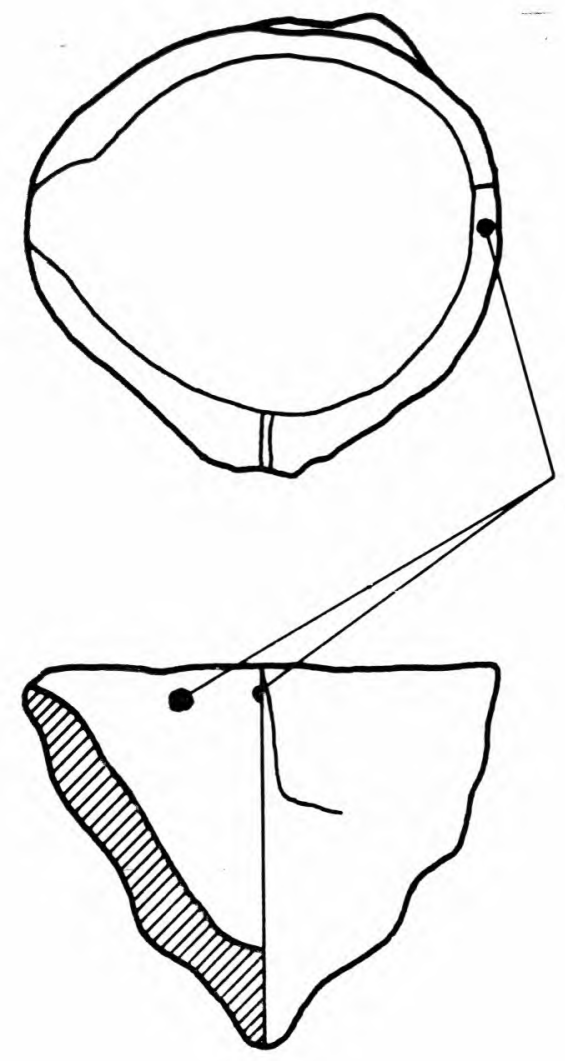

(a)

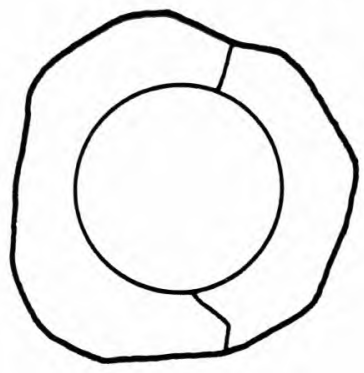

Pingos de fundição
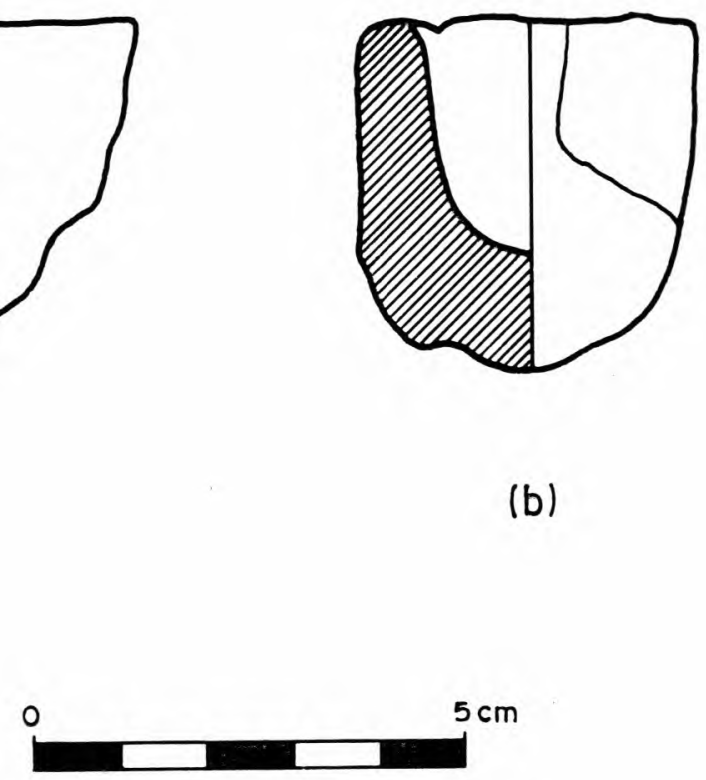

Fig. 1 - Cadinhos: (a) número 53; (b) número 54. 


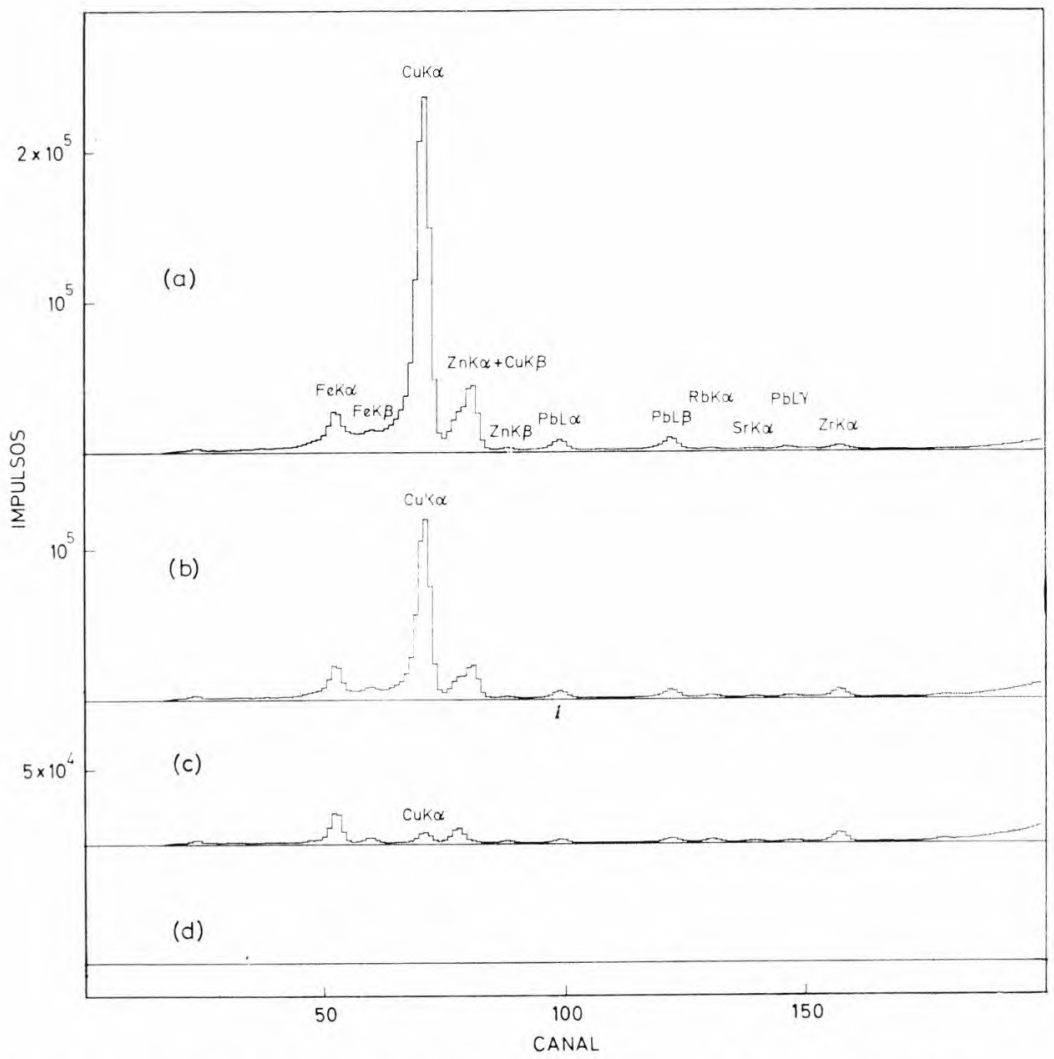

FIg. 2 - Espectros de raios $\mathrm{X}$ de diferentes regiões da superfície exterior do cadinho número 53 , obtidos fazendo a excitação com a fonte de ${ }^{109} \mathrm{Cd}$ : (a) região subjacente ao vertedoiro, onde se distingue uma faixa de tons claros; (b) região adjacente à anterior, que se observa quando se roda o cadinho cerca de $90^{\circ}$, em torno do seu eixo, a partir daquela posição no sentido contrário ao do movimento dos ponteiros do relógio; (c) região oposta à subjacente ao vertedoiro; (d) espectro da radiação de fundo, para o mesmo tempo de contagem $(800 \mathrm{~s})$. 


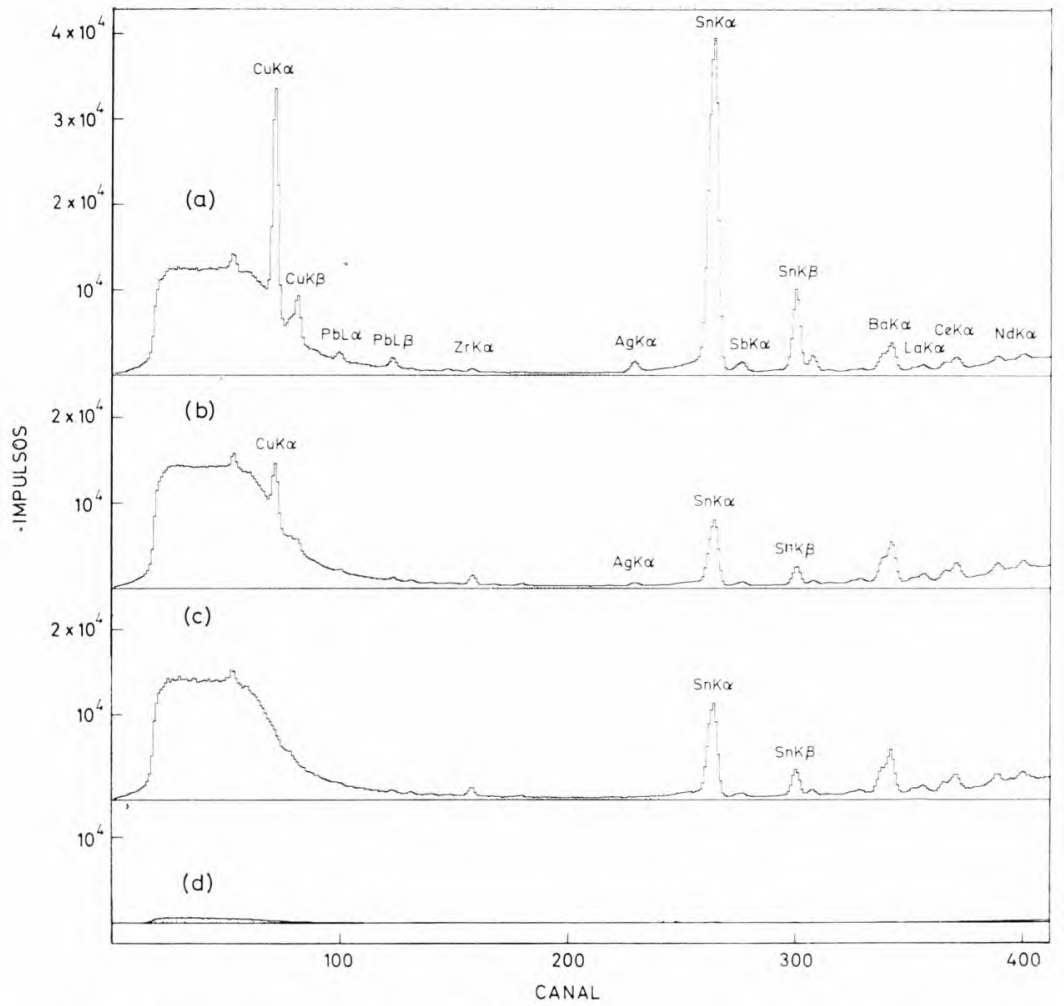

Fig. 3 - Espectros de raios $\mathrm{X}$ de diferentes regiões da superfície exterior do cadinho número 53 , obtidos fazendo a excitação com a fonte de ${ }^{241} \mathrm{Am}$ : (a) região subjacente ao vertedoiro, onde se distingue uma faixa de tons claros; (b) região adjacente à anterior, que se observa quando se roda o cadinho cerca de $90^{\circ}$, em torno do seu eixo, a partir daquela posição no sentido contrário ao do movimento dos ponteiros do relógio; (c) região oposta à subjacente ao vertedoiro; (d) espectro da radiação de fundo, para o mesmo tempo de contagem (4000 s). 


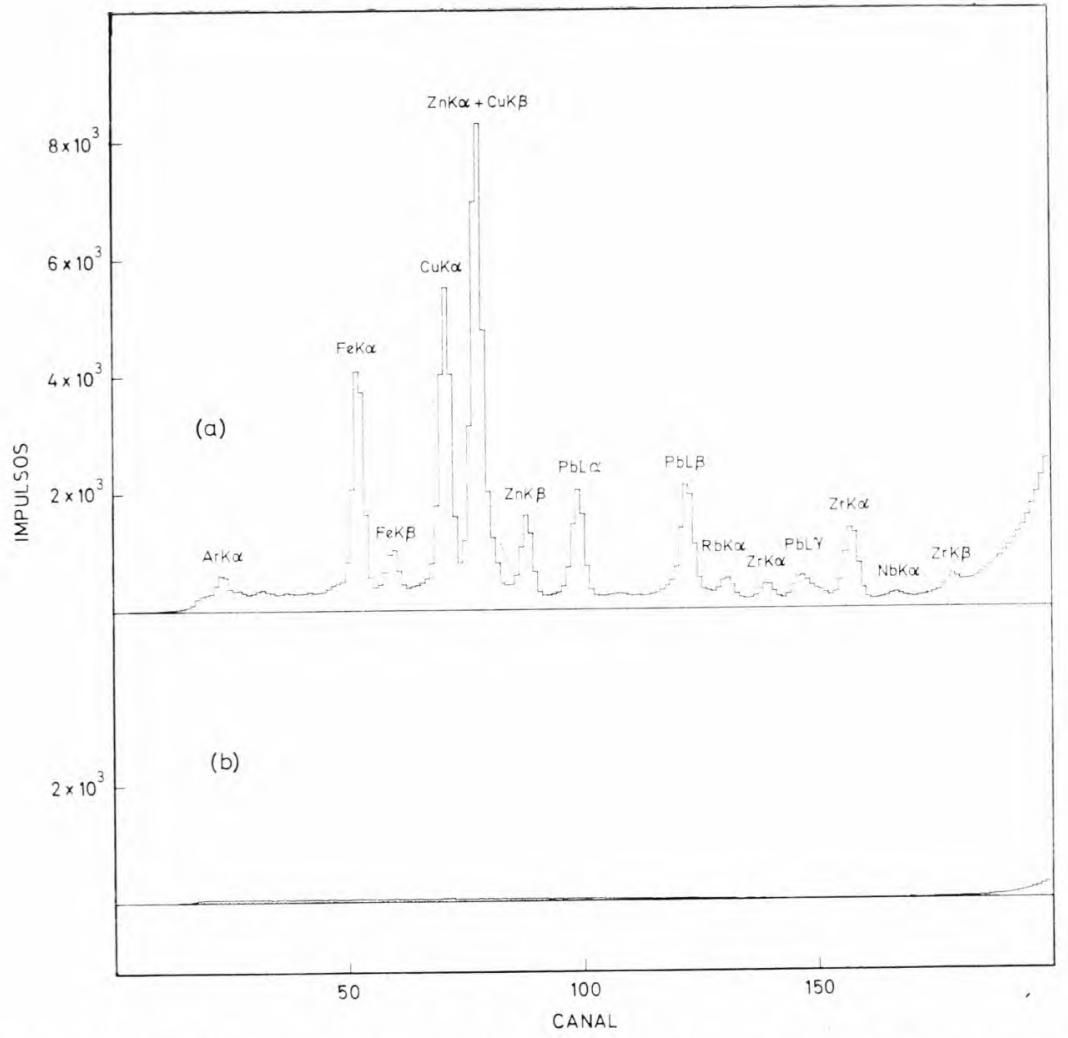

FIG. 4-(a) Espectro de raios $\mathrm{X}$ da superfície interior do cadinho número 53, obtido fazendo a excitação com a fonte de ${ }^{109} \mathrm{Cd}$. (b) Espectro da radiação de fundo, para o mesmo tempo de contagem (4000 s). 


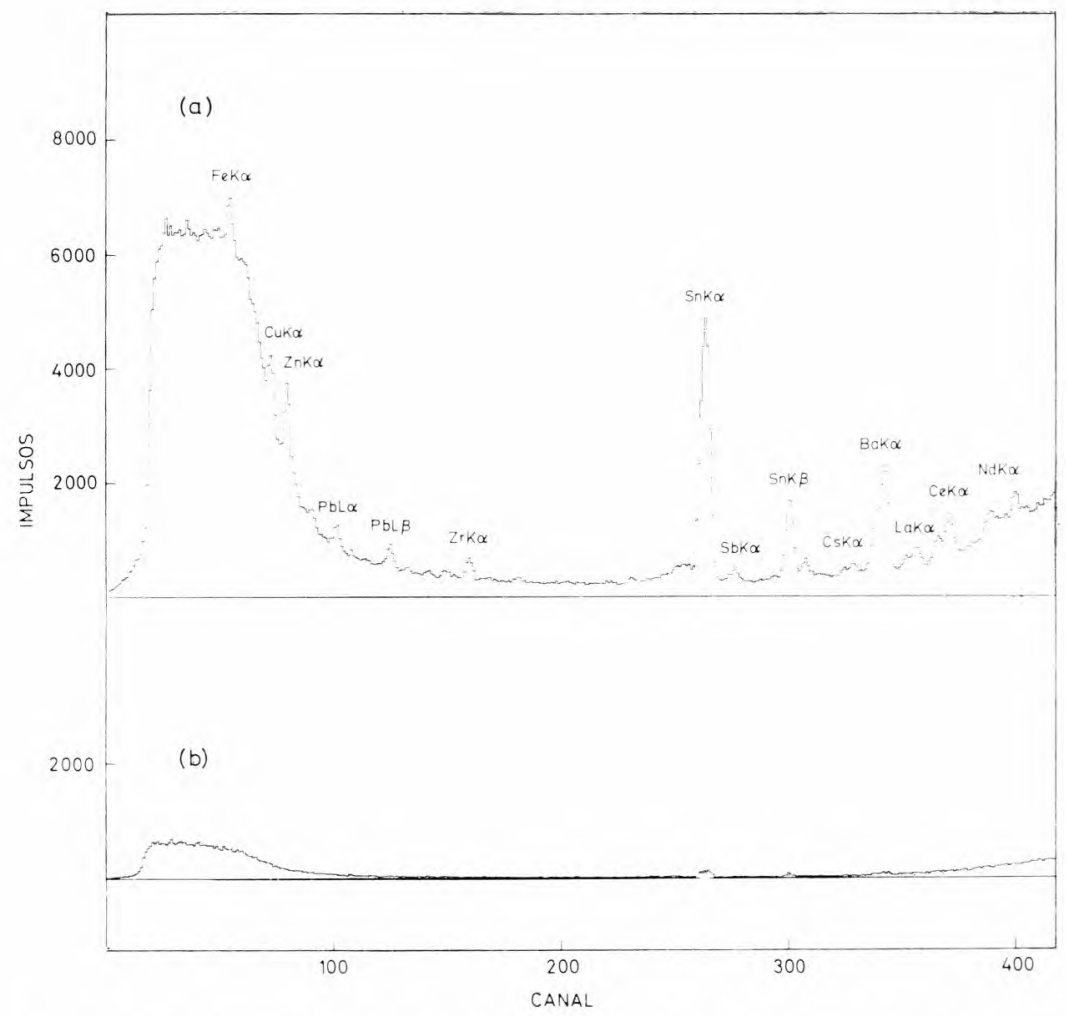

Fıg. 5 - (a) Espectro de raios $\mathrm{X}$ da superfície interior do cadinho número 53, obtido fazendo a excitação com a fonte de ${ }^{241} \mathrm{Am}$. (b) Espectro da radiação de fundo, para o mesmo tempo de contagem (4000 s). 


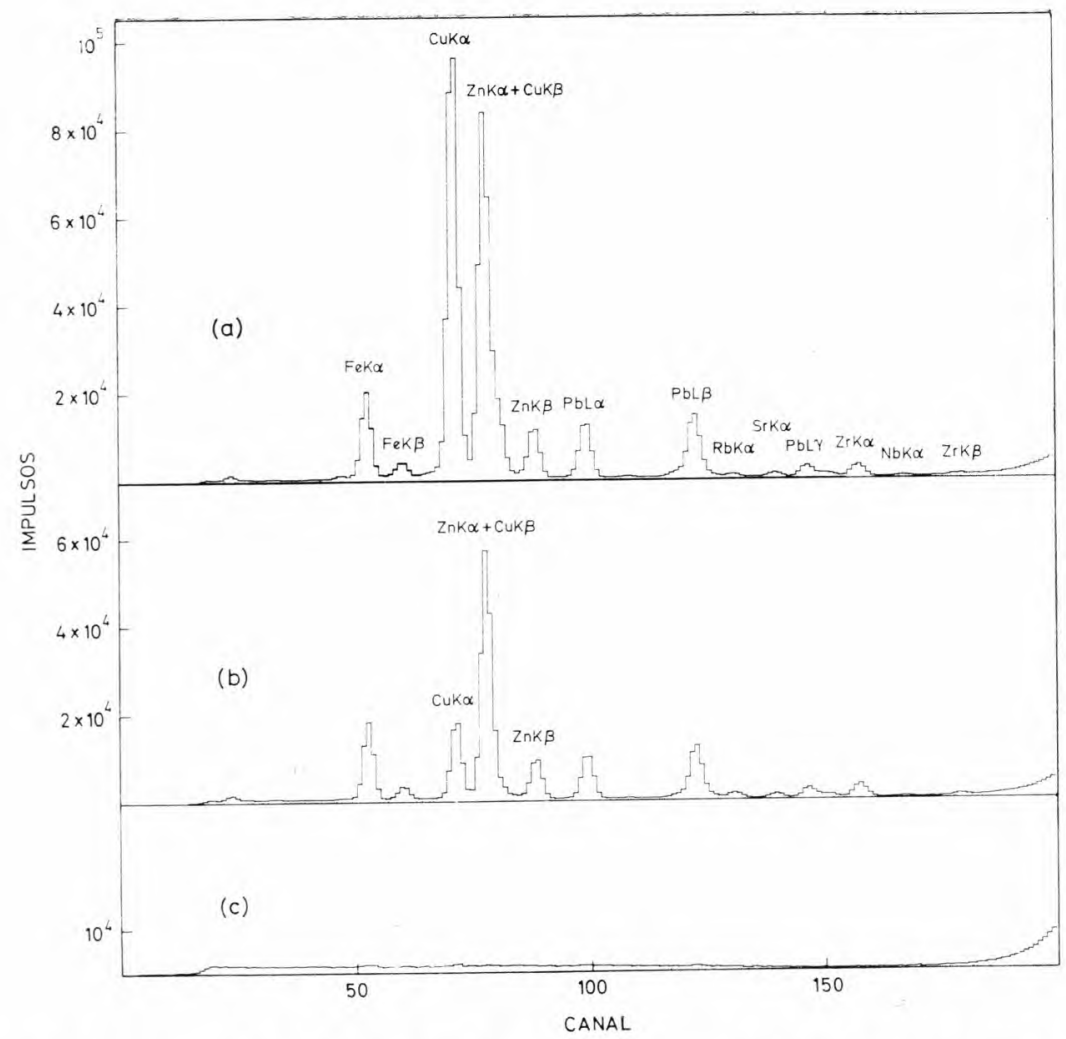

FIG. 6- Espectros de raios $\mathrm{X}$ da pequena lasca retirada da face interna do cadinho número 53 , obtidos fazendo a excitação com a fonte de ${ }^{109} \mathrm{Cd}$ : (a) da superfície exterior, onde se observavam vestigios de um pequeno pingo de fundição; (b) da superfície interior ; (c) espectro da radiação de fundo, para o mesmo tempo de contagem $(4000 \mathrm{~s})$. 


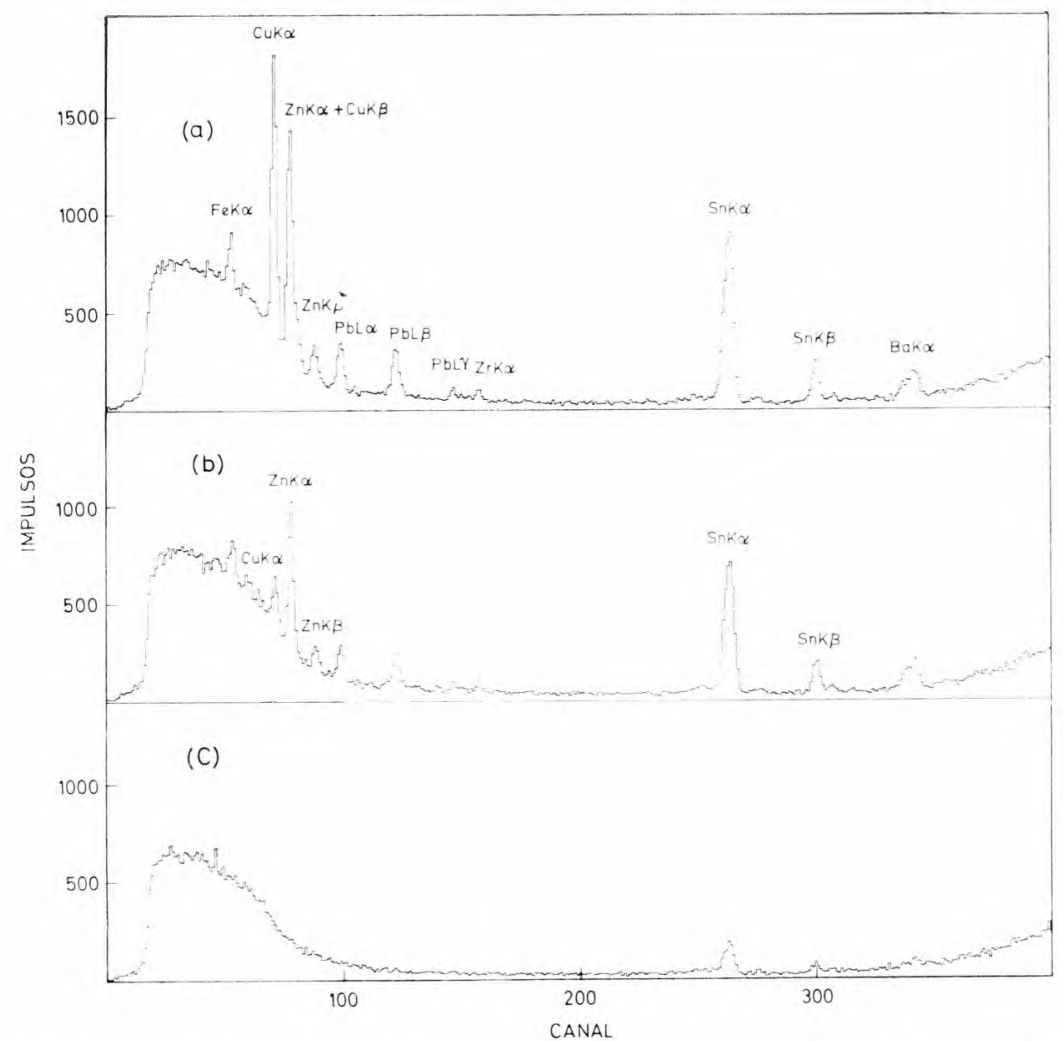

FIG. 7 - Espectros de raios $\mathrm{X}$ da pequena lasca retirada da face interna do cadinho número 53 , obtidos fazendo a excitação com a fonte de ${ }^{241} \mathrm{Am}$ : (a) da superfície exterior, onde se observavam vestígios de um pequeno pingo de fundição; (b) da superfície interior; (c) espectro da radiação de fundo, para o mesmo tempo de contagem $(4000 \mathrm{~s})$. 


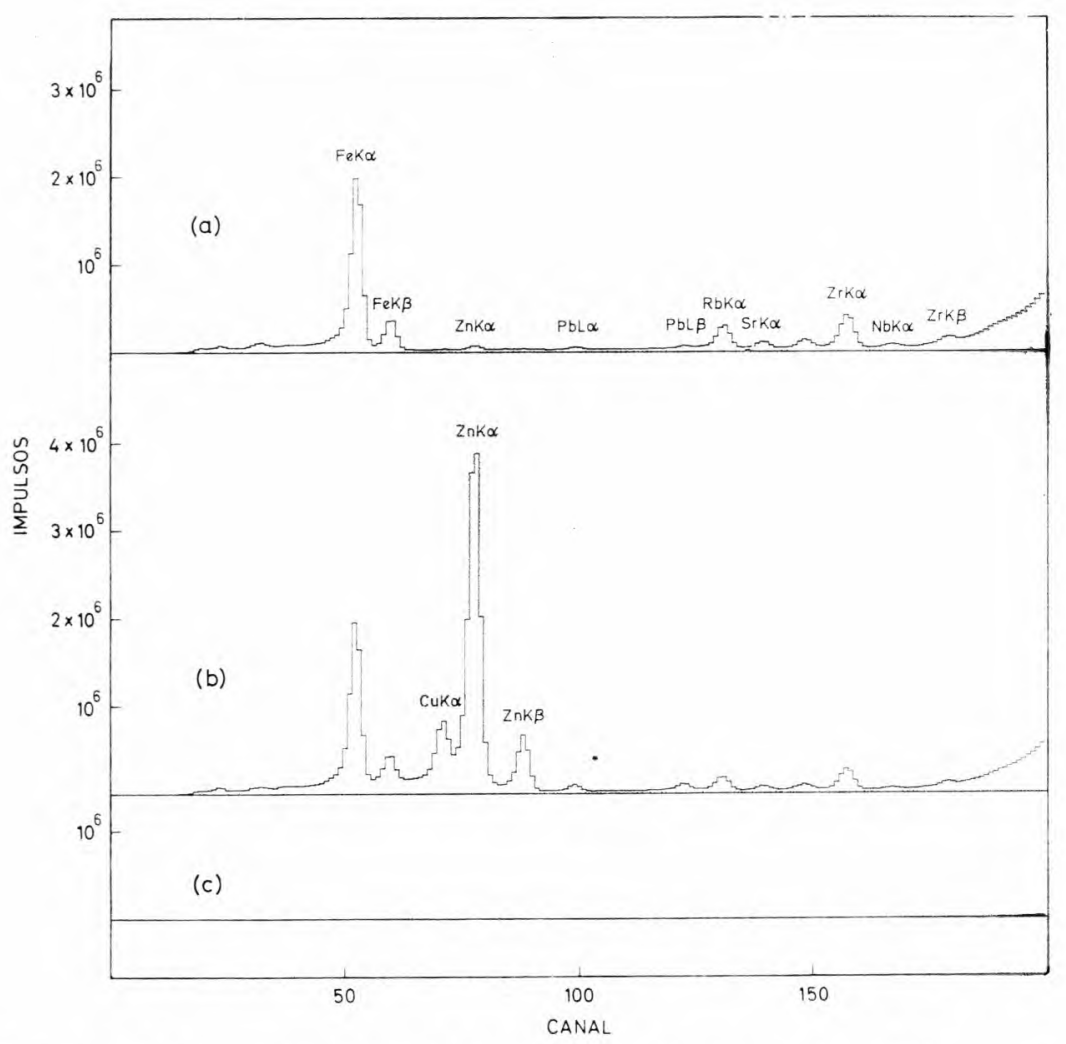

FIG. 8 - Espectros de raios $\mathrm{X}$ do fragmento mais pequeno do cadinho número 54 , obtidos fazendo a excitação com a fonte de ${ }^{109} \mathrm{Cd}$ : (a) da superfície exterior; (b) da superfície interior; (c) espectro da radiação de fundo, para o mesmo tempo de contagem (4000 s). 


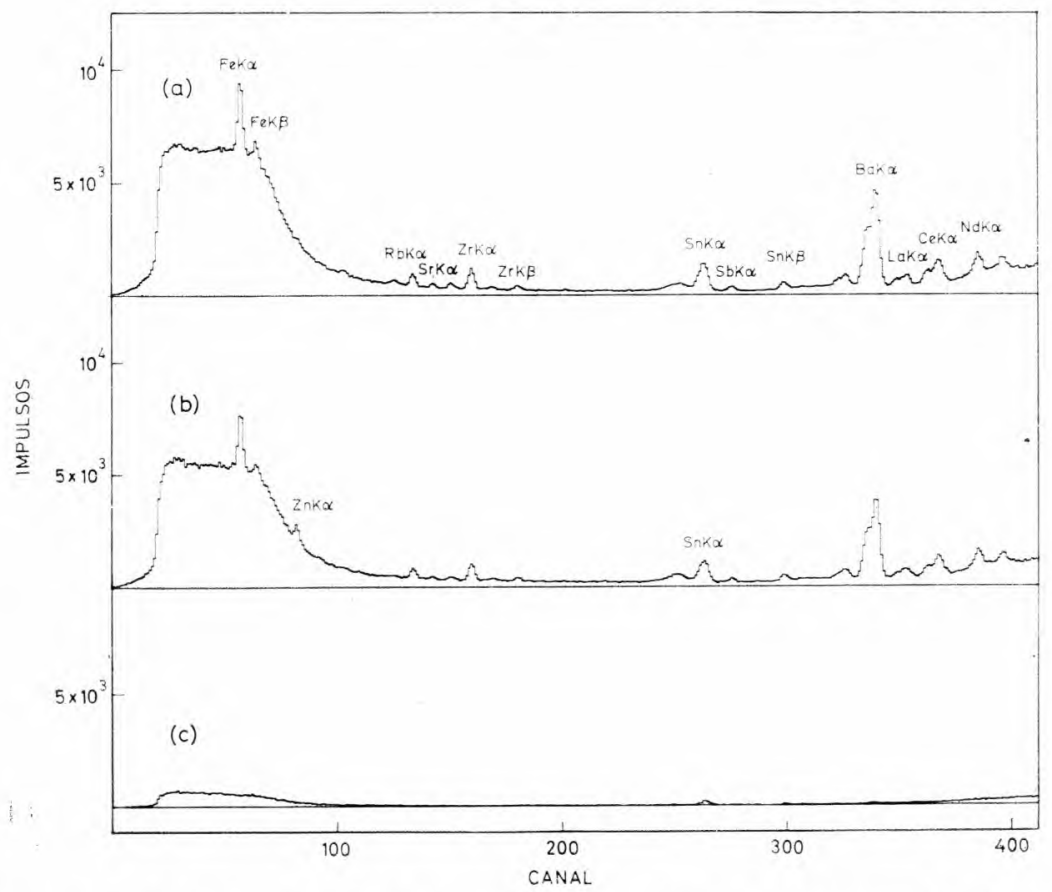

FIG. 9 - Espectros de raios $\mathrm{X}$ dum fragmento do cadinho número 54, obtidos fazendo a excitação com a fonte de ${ }^{241} \mathrm{Am}$ : (a) da superfície exterior; (b) da superfície interior; (c) espectro da radiação de fundo, para o mesmo tempo de contagem (4000 s). 